\title{
INFLUENCE MECHANISM OF VISUAL PERCEPTION OF EDGE RATE LINES CYCLE LENGTH ON DRIVER'S SPEED
}

\author{
Bing LIU $^{1^{*}}$, Shunying ZHU², Hong WANG ${ }^{3}$, Jing XIA ${ }^{4}$, Naikan DING \\ 1,2,3,4School of Transportation, Wuhan University of Technology, China \\ ${ }^{5}$ School of Civil Engineering and Architecture, Wuhan Institute of Technology, China
}

Submitted 6 November 2018; resubmitted 24 June 2019; accepted 18 July 2019;

first published online 19 August 2020

\begin{abstract}
It is known that the installation of edge rate lines can help reduce driving speed. Theoretically, higher edge rate density leads to higher perception speed, so as the effect of speed reduction. However, there has not been a successful evaluation of appropriate design cycle length requirements. A series of experiments were taken on the straight sections on Hangrui highway in China. The cycle length was separately set in different values of 16, 8, 4, 2 and $1 \mathrm{~m}$. The results showed that cycle length had significantly influence on the speed reduction effect. When the length of spatial edge rate line in each cycle $\lambda$ equalled to the value of $16,8,4,2 \mathrm{~m}$, the effect of speed reduction was significantly enhanced as $\lambda$ decreased. Percent of average speed reduction was $0.8,3.0,5.8$ and $7.4 \%$, respectively. However, when $\lambda=1 \mathrm{~m}$, speed reduction effect was weaker than $\lambda=2 \mathrm{~m}$, reduction percent of average speed was $5.2 \%$. Then, relations between acceleration and average edge rate was analysed. When temporal frequency of edge rate lines fell in $(10 \mathrm{~Hz}, 19 \mathrm{~Hz}]$, the braking deceleration of drivers increased as the temporal frequency increased, which conformed to the relation between temporal frequency and perception speed; when temporal frequency was lower than $10 \mathrm{~Hz}$, some drivers will speed up. It may be related to the threshold of perception speed difference; when temporal frequency was higher than $19 \mathrm{~Hz}$, some drivers will speed up. It may be related to flicker fusion phenomenon. According to the experiments results, edge rate lines cycle length for future implementations should be determined by the speed distribution of the target road.
\end{abstract}

Keywords: driver, speed, edge rate, cycle length, driver's speed perception, speed reduction, road experiment, temporal frequency.

\section{Introduction}

In China, there were 63093 deaths and 226430 injuries reported in over 8.6 million road traffic crashes in 2016 (TMB PSM 2017). It is reported that about $30 \%$ of the fatal vehicle crashes resulted from speeding in the US (NHTSA 2017). Thus, how to control speed and the speed-variance is the key to reduce the crashes in both severity and quantity. Road edge rate line is a special marking line designed based on the edge rate theory and laid on the both sides of road along the driving direction or across the lanes with certain specified interval, which can induce the behaviour of drivers and helps drivers to slow down. Edge rate is defined as the number of edges or intervals through the vision field of observer in unit time and its unit is $[\mathrm{Hz}]$ or [cycles/s] (Ding et al. 2019). To drivers, edge rate is an important source for drivers to perceive speed. If the texture elements' interval of edge rate line is known, the observer will be able to get the information of speed, and with edge rate increasing, the speed perceived by observers is higher. By employing the virtual-reality experiments, François et al. (2011) found that edge rate could cause overestimation in self-speed of drivers. In computer vision theory, speed was the ratio of temporal frequency to spatial frequency, temporal frequency refers to the presenting periodicity of stimuli per second and the unit of temporal frequency is $[\mathrm{Hz}]$ or $[\mathrm{cycles} / \mathrm{s}]$, spatial frequency was the intermittent number of stimuli in unit length (Saffarian et al. 2015), it is the reciprocal of periodicity length of intermittent in essence, edge rate is temporal frequency, higher speed can be perceived with the increase in edge rate. Some researchers studied the influence of temporal frequency on speed perceiving and found that the increment of temporal frequency will cause the increase

*Corresponding author. E-mail: lyhs56@126.com

Copyright $\odot 2020$ The Author(s). Published by Vilnius Gediminas Technical University

This is an Open Access article distributed under the terms of the Creative Commons Attribution License (http://creativecommons.org/licenses/by/4.0/), which permits unrestricted use, distribution, and reproduction in any medium, provided the original author and source are credited. 
of perceptual speed (Thompson 1982; Shen et al. 2005). Research by Recarte and Nunes (1996) showed that the actual speed of vehicle will decreased as the perceptual speed increased, the increment of perceptual speed to the reduction of actual speed was about 2:1, on the contrary, the decrease of the perceptual speed will also cause the increase of actual speed. Therefore, it is a feasible measure to reduce the actual speed of vehicles by increasing the perceptual speed of drivers.

The application of edge rate theory has been widely used to reduce speed at hazardous section. It is usually applied in the installation of transverse or edge line markings. Denton (1980) utilized the edge rate firstly to reduce vehicles' speed in 1980, by laying edge rate lines with a certain interval on the upper lanes of a traffic circle, which reduced both the vehicles' speed and the accident rate. In the US, the "chevron" markings with decreasing gaps were paved on the streets in a community, after a week, 85th percentile speed decreased $15 \%$ and the highest speed decreased $20.9 \mathrm{~km} / \mathrm{h}$, two years later, 85th percentile speed decreased 5\% (ATSSA 2006). Retting et al. (2000) found out the speed perception has effect on speed reduction, especially for personal vehicles and trucks. Another study by Godley et al. (2000) evaluated transverse lines as well as peripheral transverse lines versus a control section of roadway in a driving simulator. Transverse lines are stripes that are placed across the entire travel lane whereas the peripheral transverse lines are placed only on the edges of the travel lane. The study showed that driving speeds were only slower for the transverse lines (as compared to the peripheral transverse lines) for the initial section of treatment but that overall, the peripheral lines performed the same and in some cases better than the regular transverse lines at the beginning of the treatment area where the mean speed of transverse lines was $92 \mathrm{~km} / \mathrm{h}(57 \mathrm{mi} / \mathrm{h})$ and the mean speed of the peripheral transverse lines was $98 \mathrm{~km} / \mathrm{h}(61 \mathrm{mi} / \mathrm{h})$ at the beginning of the treatment. A study on forced deceleration facilities in University of Massachusetts (MassSAFE 2004) showed that transverse lines with gradually decreasing intervals paved on the whole lanes could dramatically reduce the speed. A study by Rakha et al. (2006) evaluated peripheral transverse lines spaced at a frequency of 4 lines/s in New York, Mississippi, and Texas. The markings were applied on approaches to curves in both rural and urban environments on both multi-lane and two-lane roadways. The authors concluded that overall, the pavement markings reduced the adjusted speeds up to $15.3 \mathrm{~km} / \mathrm{h}(9.5 \mathrm{mi} / \mathrm{h})$ on overall vehicle speeds when comparing total vehicles, two axle vehicles, vehicles with more than two axles, and particularly with vehicles following further than four seconds behind the previous vehicle. Hallmark et al. (2013) carried out road experiments on rural roads in Iowa, and found that edge rate marking can achieve a certain speed reduction effect. Liu et al. (2013) studied the influence of the plane layout of the edge rate lines on the speed reduction effect, and found that the double-row edge rate lines had better speed reduction effect. Furthermore, through road experiments, Ding et al. (2017a, 2017b, 2019) found that edge rate marking can not only reduce the speed, but also increase the headway time, the cycle length of edge rate lines selected by the experiment were $2 \mathrm{~m}$.

In summary, although evaluations have been performed to determine their effectiveness, there has not been a successful evaluation of appropriate design cycle length requirements. Higher temporal frequency would increase the speed perception according to the definition of edge rate; shorter cycle length of edge rate lines should reduce speed much better. Therefore, the goals of this study are to:

"» determine edge rate lines cycle length for evaluation; "» evaluate the effectiveness of the edge rate lines;

"'» provide recommendations for edge rate lines cycle length design for future implementations.

\section{Road experiments}

\subsection{Section selection}

The edge rate lines were tested on Hangrui highway in China. It is two-way four-lane highway. The design speed is $100 \mathrm{~km} / \mathrm{h}$, the speed limit is $100 \mathrm{~km} / \mathrm{h}$ and the lane-width is $3.75 \mathrm{~m}$. This experimental section is a long straight section without any tunnel and overpass in a $300 \mathrm{~m}$ area, and the longitudinal slope of experimental section is $0.5 \%$. There is no surveillance system (i.e. Closed-Circuit TeleVision - CCTV) for driving violation. This highway was put into use 3 month before this study. Therefore traffic volume was small and it was assumed to be free flow.

\subsection{Edge rate lines installation}

The total length of experimental edge rate lines was $300 \mathrm{~m}$ for two road experiments and they were adhesive and retroreflective, as shown in Figure 1. The optical properties were conformed to the guidelines in China. The colour for

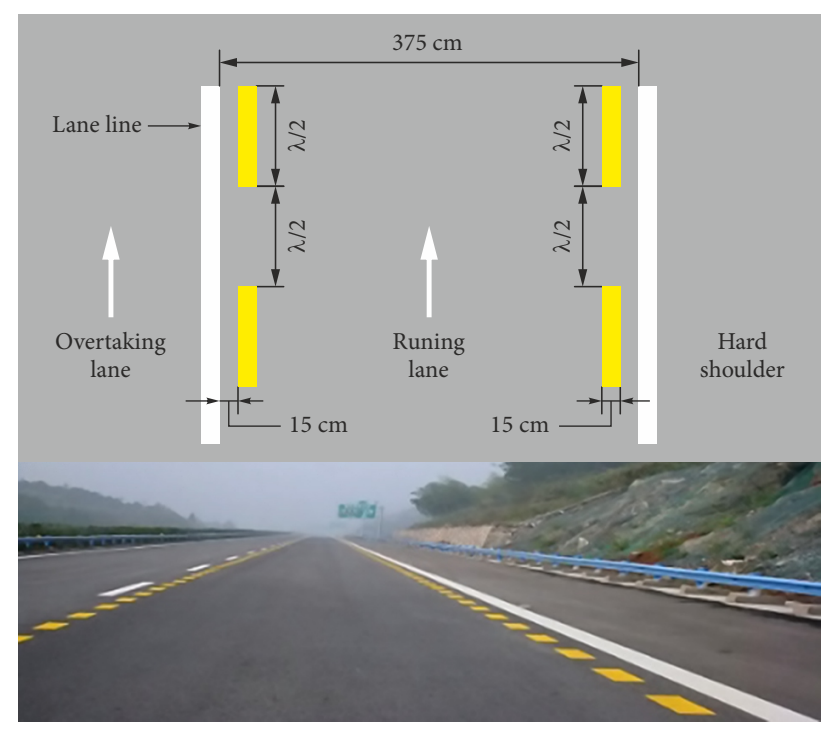

Figure 1. Edge rate lines designed 
each row was the same to remove the influence raised by the colours. Here $\lambda$ represents the length of spatial edge rate line in each cycle (including a piece of marking line and an interval). In this experiment, $\lambda$ had 3 kinds of values: 8,4 and $2 \mathrm{~m}$. The length of single edge rate line and the interval between lines is $\lambda / 2$. The width and lateral interval to the established lane markings are all $15 \mathrm{~cm}$. The cycle length $\lambda$ of the lane boundary between the running lane and the overtaking lane is $15 \mathrm{~m}$.

\subsection{Data collection}

The observations were taken in the daytime and in the clear weather conditions.

NC200 Nu Metrics Portable Traffic Analyser was used in this study to collect data about traffic characteristics such as space speed, headway, and vehicle type (classified by the length of vehicle). There were two data collection periods reported in this study. The first was prior to the installation of the edge rate lines. The second data collection period took place after the installation. There were 7 data collection sections. Data collected from sections 1 ...6 were used to rule out non-free traffic flows. Data collected from section 2 also were used to analyse the edge rate when vehicle passed the experimental segment. Data collected from section 6 also were used to evaluate the reduction of speed (Figure 2). The working performance of devices was compared to the results from radar gun periodically for accuracy. In order to avoid possible malfunction of the instrument, radar guns were used to manually sample the vehicle speed data during the experiment, and if the NC200 Nu Metrics Portable Traffic Analyser data were significantly different from the manual sampling data, the observation was conducted again. The data collection was carried out one week after the edge rate lines were laid. In addition, a digital video camera was used to record video documents. In summary, the observations were selected during clear weather periods, and there were no construction, road obstructions, and temporary stopin vehicles on the observed road sections.

\subsection{Data analysis}

The statistical analysis for the experiment was directed at determining relative effectiveness between edge rate treatments on speed. Parametric statistical techniques were employed with an alpha significance level of $p=0.05$.

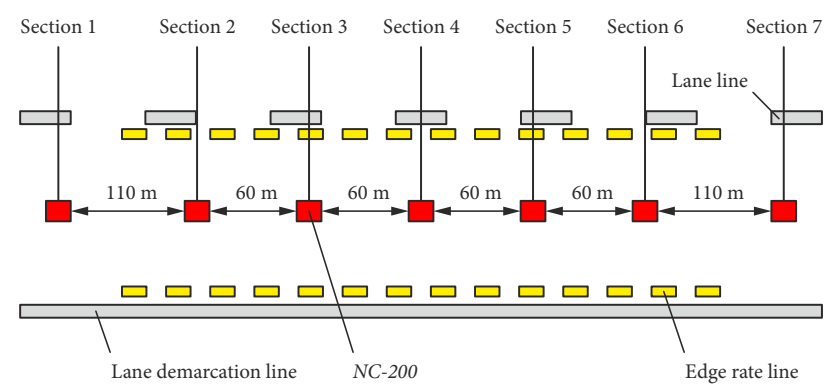

Figure 2. Layout of the NC200 Nu Metrics Portable Traffic Analyser (red squares represent NC200)
Rejection of the non-free traffic flows. The speed of unstable free flow vehicles was influenced by the front car besides edge rate lines. Thus, researchers had to rule out non-free traffic flows to keep data accuracy. The stop time $t$ could be calculated according to the speed collected at each section and common deceleration $2.5 \mathrm{~m} / \mathrm{s}^{2}$ (AASHTO 2011). Then the headway was compared to the stopping time. A vehicle was regarded as a non-free vehicle if $t<$ headway. The value range for $t$ is from 7.79 to $14.81 \mathrm{~s}$.

Rejection of the lane changing vehicles. The lane change happened during the driving. To avoid the negative effect of lane changing vehicles, researchers adopted manual interpretation to rule out the vehicles for accuracy. In the experiment, observation videos were used to distinguish and reject lane change vehicles. After the data collection was completed, the vehicle license plate number was used to remove lane changing vehicles.

\section{Experiment results}

\subsection{Inspection of minimum sample size}

After eliminating, the improper data is to calculate of minimum sample size. According to the statistical characteristics of data in each scheme and at each observation section, researchers have calculated the minimum sample size of each scheme, as shown in Table 1. In each single scheme, it has difference of average and variance of data between different sections. Therefore, the minimum sample size of each section may be different, too. The minimum sample size of this section is taken as the minimum sample size of the scheme (observation error of vehicle speed can be $\pm 0.25 \mathrm{~m} / \mathrm{s}$ ).

Table 1 . The minimum sample size and actual sample size

\begin{tabular}{|l|c|c|c|c|c|c|}
\cline { 2 - 7 } \multicolumn{1}{c|}{} & $\begin{array}{c}\text { Pre-instalment } \\
{[\mathrm{m}]}\end{array}$ & \multicolumn{5}{|c|}{$\lambda[\mathrm{m}]$} \\
\cline { 3 - 7 } & 248 & 252 & 208 & 191 & 167 & 224 \\
\hline $\begin{array}{l}\text { Minimum } \\
\text { sample size }\end{array}$ & 362 & 371 & 388 & 349 & 380 & 380 \\
\hline $\begin{array}{l}\text { Actual } \\
\text { sample size }\end{array}$ & 362 & \multicolumn{5}{|c|}{} \\
\hline
\end{tabular}

\subsection{Effects on speed for all vehicles at section 6}

The average speed, 85th speed and standard deviations at section 6 were counted (Figure 3). In order to determine the appropriate statistical tests, it was necessary to determine if the data could be approximated with a normal distribution. Figure 3 shows the speed distribution of the section 6 speed data before and after installation of the edge rate lines. The Shapiro-Wilk (sample size $<2000$ ) goodness-of-fit test indicated that the data was normally distributed at the 0.05 level.

The results of experiments indicated the following features:

"» in the five laying schemes of edge rate lines, the average value and standard deviation of speed is significantly reduced, comparing with the speed before laying (the observed results in different schemes 
and un-laid condition were respectively calculated in one-way ANalysis Of VAriance (ANOVA), which all get $p<0.05)$. Before laying, when $\lambda=16,8,4,2$, $1 \mathrm{~m}$, the average value of speed successively were $28.52,28.28,27.68,26.88,26.41,27.05 \mathrm{~m} / \mathrm{s}$ and the standard deviation of speed were $2.19,2.01,1.89$, $1.81,1.56,1.89 \mathrm{~m} / \mathrm{s}$. When testing for statistical significance between the pre-instalment and after speeds of the section 6 , the mean difference was significant at the 0.05 level using ANOVA;

"») when $\lambda$ equalled to the value of $16,8,4,2 \mathrm{~m}$, the effect of speed reduction was significantly enhanced as $\lambda$ decreased. The proportions of average speed reduction successively were $0.8,3.0,5.8$ and $7.4 \%$ (the mean difference was statistically significant at the 0.05 level using ANOVA). The proportions of standard deviation reduction were 8.7, 14.7, 18.7 and $29.8 \%$ (the mean difference was statistically significant at the 0.05 level using ANOVA);

"» when $\lambda=1 \mathrm{~m}$, the average speed, 85th speed and standard deviation of speed reduced 7.51, 0.52 and $8.75 \mathrm{~km} / \mathrm{h}$ respectively. In addition, the reduction calculated as percentage was $5.2,14$ and $3.0 \%$, the speed reduction effect was weaker than $\lambda=2 \mathrm{~m}$. When testing for statistical significance between the pre-instalment and after speeds of the section6, the difference was significant at the 0.05 level using ANOVA.

\subsection{Effects on speed by vehicle classification at section 6}

As the small vehicle (length $<7 \mathrm{~m}$ ) and oversize vehicle (length $\geq 7 \mathrm{~m}$ ) took over $98 \%$ of valid data, the following analysis are based on vehicle classifications. The average speed, 85th speed and standard deviations at section 6 were counted, as shown in Table 2 . The general trends of the speed reduction effects were consistent with what were seen in the analysis of all vehicles, as shown in Figure 4.

\subsection{Effects on speed change between sections 2 and 6}

Speed change between sections 2 and 6 were calculated, as shown in Figure 5. In general, a lowering of the average driving speed, which corresponds with an effect size of less than zero, is regarded as an improvement of road safety. Both decreases and increases of the average speed were found. When $\lambda$ equalled to the value of $16,8,4,2 \mathrm{~m}$, the curve was shifted to the left, suggesting the speed reduction effect was enhanced as $\lambda$ decreased. a)

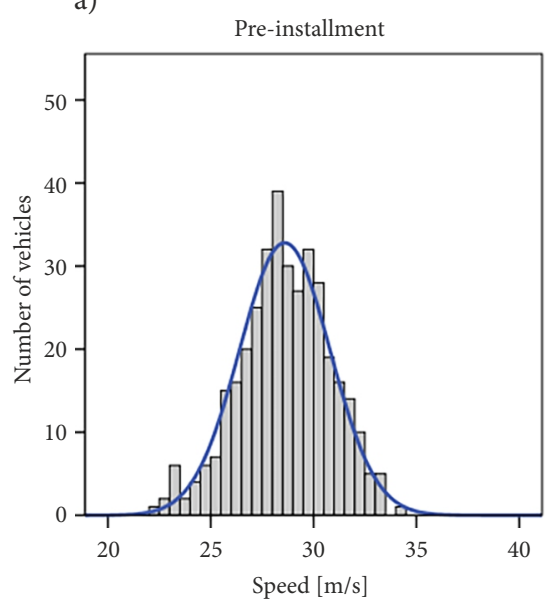

d)

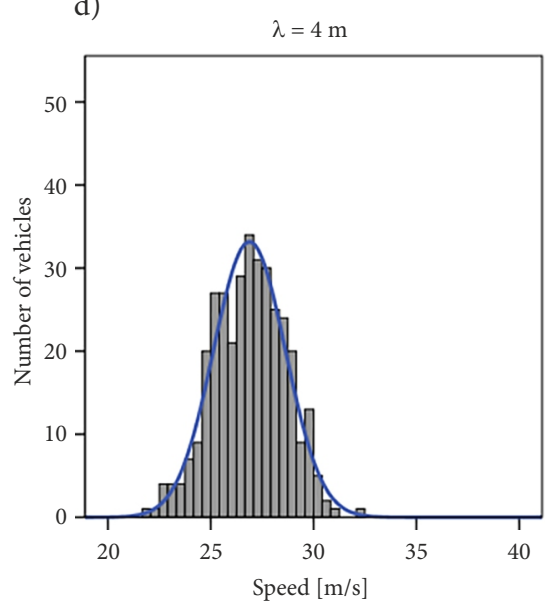

b)

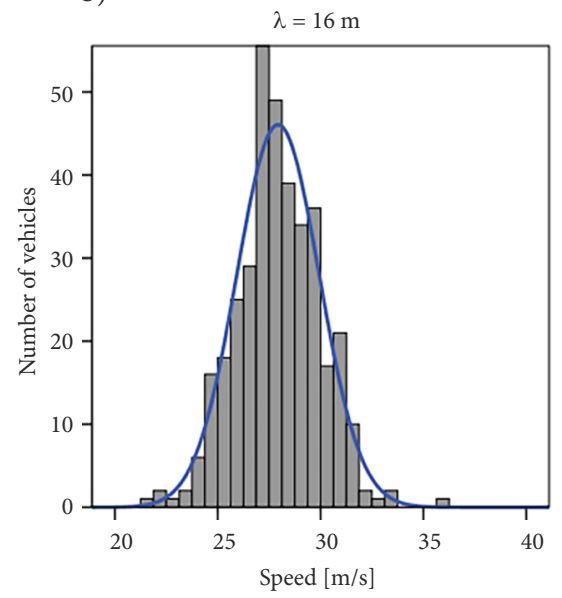

e)

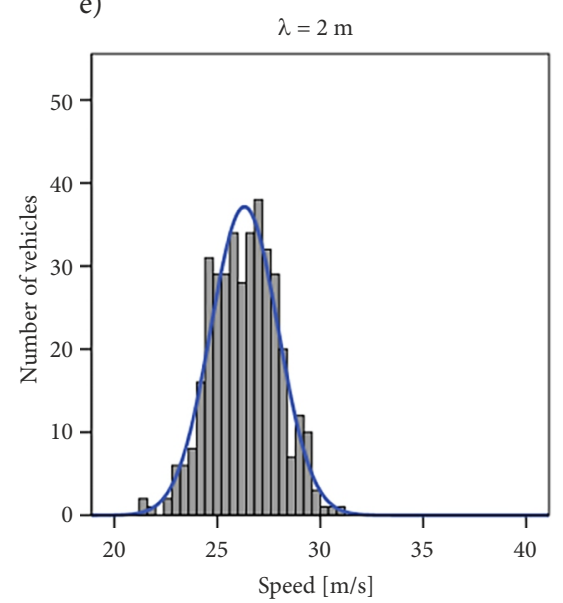

c)

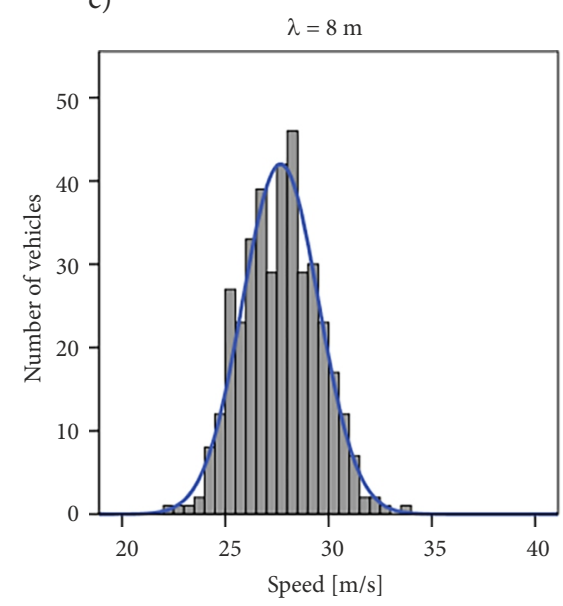

f)

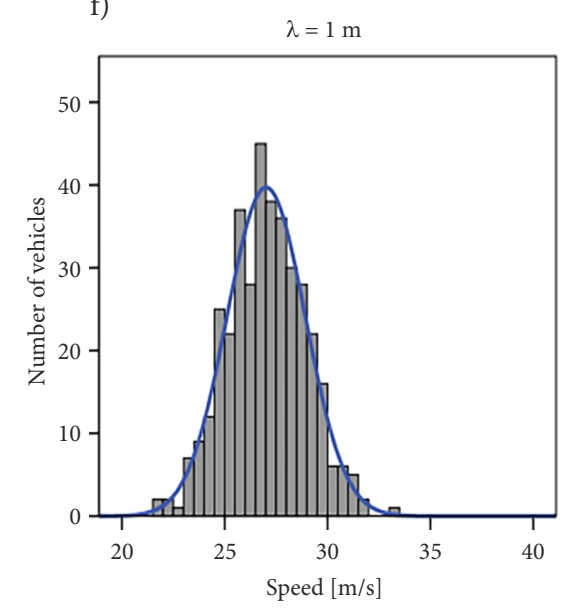

Figure 3. Effects on speed of all vehicles at section 6 
Table 2. Speed index by vehicle classification

\begin{tabular}{|c|c|c|c|c|c|c|}
\hline & \multirow{2}{*}{ Pre-instalment [m] } & \multicolumn{5}{|c|}{$\lambda[\mathrm{m}]$} \\
\hline & & 16 & 8 & 4 & 2 & 1 \\
\hline \multicolumn{7}{|c|}{ Small vehicles } \\
\hline Average speed $[\mathrm{m} / \mathrm{s}]$ & 29.38 & 29.13 & 28.51 & 27.68 & 27.21 & 27.86 \\
\hline Standard deviation $[\mathrm{m} / \mathrm{s}]$ & 2.25 & 2.03 & 1.92 & 1.83 & 1.58 & 1.92 \\
\hline 85th speed $[\mathrm{m} / \mathrm{s}]$ & 33.44 & 33.27 & 32.83 & 32.15 & 30.86 & 32.43 \\
\hline \multicolumn{7}{|c|}{ Oversize vehicles } \\
\hline Average speed $[\mathrm{m} / \mathrm{s}]$ & 25.38 & 24.06 & 24.08 & 23.92 & 23.70 & 24.08 \\
\hline Standard deviation $[\mathrm{m} / \mathrm{s}]$ & 1.95 & 1.58 & 1.65 & 1.61 & 1.38 & 1.68 \\
\hline 85th speed $[\mathrm{m} / \mathrm{s}]$ & 28.90 & 27.36 & 26.98 & 27.22 & 26.67 & 28.30 \\
\hline
\end{tabular}

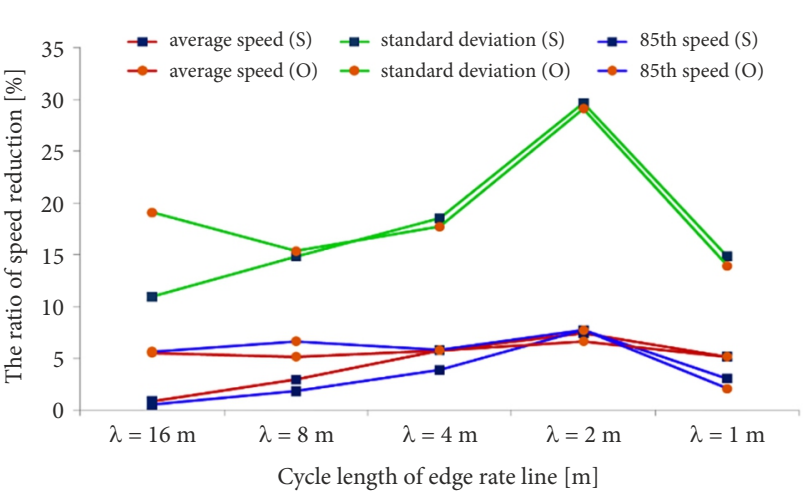

Figure 4. Effects on speed of vehicles by vehicle classification ( $\mathrm{S}$ - small vehicles, $\mathrm{O}$ - oversize vehicles)

On basis of the above analysis, a further statistical analysis was taken about the percent of vehicles slowing between sections 2 and 6 (Table 2). After instalment of edge rate lines, the percent of vehicles slowing between sections 2 and 6 is significantly more than $50 \%$ by all the vehicles (according to one-way ANOVA, $p<0.05$ ). When $\lambda$ equalled to the value of $16,8,4,2 \mathrm{~m}$, the percent was significantly increased as $\lambda$ decreased the difference was significant at the 0.05 level using ANOVA.

\subsection{Effects of temporary frequency on acceleration}

Since the speed of vehicles is dynamic, the average acceleration and temporary frequency of a single vehicle running between sections 2 and 6 was chosen to simplify the analysis. Equations (1) and (2) are the calculated method of average acceleration speed and temporary frequency respectively:

$$
\bar{a}_{i}=\frac{v_{6 i}-v_{2 i}}{t_{6 i}-t_{2 i}},
$$

where: $\bar{a}_{i}$ is the average acceleration speed between sections 2 and 6 in experiment $i\left[\mathrm{~m} / \mathrm{s}^{2}\right] ; t_{2 i}$ and $t_{6 i}$ separately represents the arrival time that vehicle arrives at sections 2 and $6[\mathrm{~s}] ; v_{2 i}$ and $v_{6 i}$ separately represents the speed that vehicle arrives at sections 2 and $6[\mathrm{~m} / \mathrm{s}]$;

$$
\overline{E R_{i}}=\frac{\frac{240}{\lambda}}{t_{6 i}-t_{2 i}},
$$

where: $\overline{E R_{i}}$ is the average edge rate while vehicle $i$ cross-

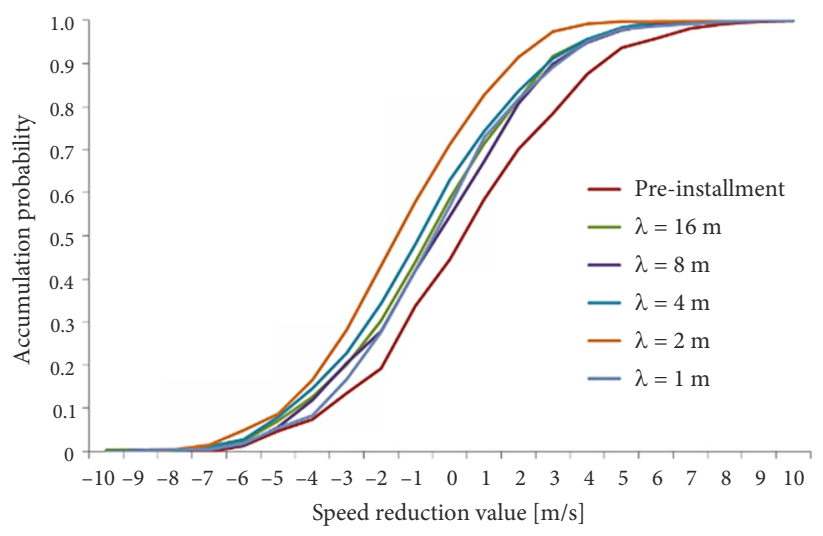

Figure 5. Speed change accumulation distribution curve

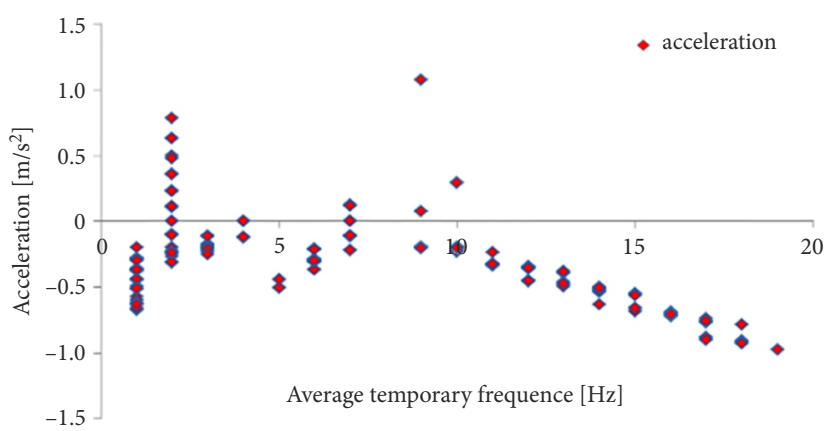

Figure 6. Relations between acceleration speed and average edge rate

ing through sections 2 and $6[\mathrm{~Hz}] ; \lambda$ is the length of edge rate line in each cycle $[\mathrm{m}]$; the distance between sections 2 and 6 is $240 \mathrm{~m}$.

Summarizing the data collected in different schemes, we can get the acceleration of single vehicle corresponding to different edge rates (note: The cycle length $\lambda$ of boundary between running lane and overtaking lane is $15 \mathrm{~m}$ ). Figure 6 showed the relation between acceleration speed and average edge rate.

When $10<E R \leq 19 \mathrm{~Hz}$, as the edge rate increased, the reduction increased progressively. The relation between temporal frequency and acceleration speed is a negative linear relationship (shown in Equation (5), with an association coefficient of $R_{2}=0.921$.

$$
a=-0.0868 \cdot a t f+0.6825 \text {, }
$$

where: $a t f$ is average temporary frequency. 


\section{Discussions}

\subsection{Influence of $\lambda$ on speed reduction}

As the $\lambda$ decreased, the temporal frequency that edge rate line moving relative to human eyes increased, the temporal frequency intervals under different $\lambda$ were calculated, as shown in Table 3. According to the relation between temporal frequency and perception speed, as the temporal frequency increased, the perception speed should increase, and then the speed reduction effect should be enhanced. When $\lambda$ equalled to the value of $16,8,4,2 \mathrm{~m}$, the phenomenon conformed to above assumption, but when $\lambda=1 \mathrm{~m}$, speed reduction effect weaker than $\lambda=2 \mathrm{~m}$. In view of this phenomenon, a further discussion was conducted.

Table 3. The temporal frequency intervals

\begin{tabular}{|c|c|c|c|c|c|}
\cline { 2 - 6 } \multicolumn{1}{c|}{} & \multicolumn{5}{c|}{$\lambda[\mathrm{m}]$} \\
\cline { 2 - 6 } \multicolumn{1}{c|}{} & 16 & 8 & 4 & 2 & 1 \\
\hline$E R$ & {$[0.94,2.28]$} & {$[1.47,5.09]$} & {$[3.50,9.68]$} & {$[8.28,21.49]$} & {$[18.54,32.71]$} \\
{$[\mathrm{Hz}]$} & & & & & \\
\hline
\end{tabular}

\subsection{Influence of temporal frequency on speed reduction}

According to Figure 6 and Equation (3), when temporal frequency was in the area of $(10 \mathrm{~Hz}, 19 \mathrm{~Hz}$, the braking deceleration of drivers increases as the increasement of temporal edge rate. That was to say that the intensity of speed reduction was increasing as the temporal frequency increased. As a result, the effect of speed reduction was enhanced. It can be explained by the relation between temporal frequency and the perception speed. As temporal frequency increased, drivers' perception speed will also increase and they will overestimate the actual speed. Then drivers will reduce their vehicle's speed actively to avoid driving dangers.

When temporal frequency was lower than $10 \mathrm{~Hz}$, some drivers will speed up. It may be related to the threshold of perception speed difference (Longo, Lourenco 2007). In addition, the threshold of the perception speed difference may also have influence on drivers' speed choice behaviour. The perception threshold of difference represents the minimum intensity difference $\Delta S$ between stimuli that cause difference feelings. It is related to the proportional constant $K$ and the original stimuli $S . \Delta S=K \cdot S$. For the same kind of stimuli, the proportional constant is in a given area, but the diversity exists between individuals. For this experiment, the proportional constant $K$ is different between different drivers and the starting speed $S$ of each experiment is also different. Therefore, the threshold of perception speed difference $\Delta S$ has diversity, too. As the temporal edge rate is lower than $10 \mathrm{~Hz}$, the increment of perception speed caused by it may be very limited. Therefore, for part of the experiments, the increments of perception speed will smaller than $\Delta S$, which cannot be felt by drivers. However, the other part of the drivers will speed up under the influence of other factors like emotions or fatigue at this time.

When temporal frequency was higher than $19 \mathrm{~Hz}$, some drivers will speed up. It may be related to flicker fusion phenomenon. Flicker fusion phenomenon results from persistence of vision (Carmel et al. 2005; Waldin et al. 2017), which is the phenomenon of the eye by which an afterimage is thought to persist for approximately one twenty-fifth of a second on the retina. When the temporal frequency increased to some extent, the afterimage may overlap the actual image, and then edge rate lines appears to be completely steady to the observer, as shown in Figure 7. Edge rate lines produced afterimages along the driving direction. The afterimages and the actual images get together in a single-row line when the line density reaches a certain value. The temporal frequency of driver's perception (the edge rate of driver's perception was called perception edge rate in this paper) was 0 . Then the driver should underestimate speed. When $\lambda=1 \mathrm{~m}$, the corresponding temporal frequency interval was $[18.54 \mathrm{~Hz}$, $32.71 \mathrm{~Hz}$ ], flicker fusion phenomenon may be occurred, then, speed reduction effect was weaker than $\lambda=2 \mathrm{~m}$.

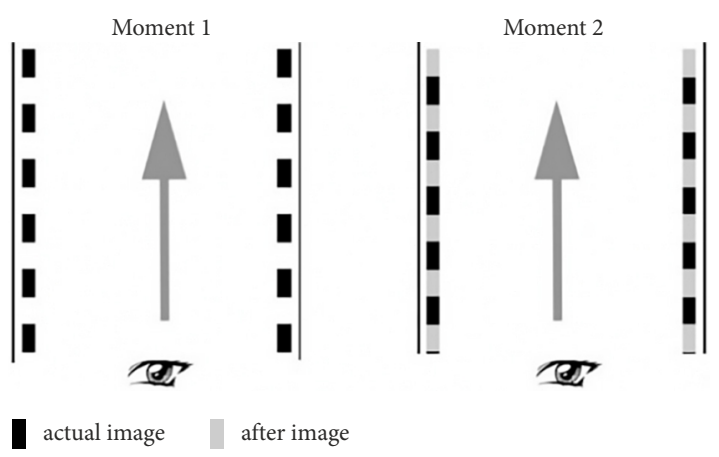

Figure 7. Schematic of persistence of vision

\subsection{Recommended cycle length of edge rate lines for speed control}

According to the results of experiments, the best cycle length of edge rate lines was $2 \mathrm{~m}$. But according to the influence of temporal frequency on speed reduction, When temporal frequency of edge rate lines fell in $(10 \mathrm{~Hz}$, $19 \mathrm{~Hz}$, the braking deceleration of drivers increases as the increment of temporal frequency, temporal frequency was a key factor which affected the speed reduction effect. Then, edge rate lines cycle length for future implementations should be determined by the speed distribution of the target road.

\section{Conclusions}

According to the study, the following conclusions can be get:

"»» cycle length had significantly influence on the speed reduction effect; when $\lambda$ equalled to the value of 16 , $8,4,2 \mathrm{~m}$, the effect of speed reduction was significantly enhanced as $\lambda$ decreased; 
"») when temporal frequency of edge rate lines fell in $(10 \mathrm{~Hz}, 19 \mathrm{~Hz}]$, the braking deceleration of drivers increased as the temporal frequency increased, which conformed to the relation between temporal frequency and perception speed; when temporal frequency was lower than $10 \mathrm{~Hz}$, some drivers will speed up. It may be related to the threshold of perception speed difference; when temporal frequency was higher than $19 \mathrm{~Hz}$, some drivers will speed up. It may be related to flicker fusion phenomenon;

"»" according to the experiments results, edge rate lines cycle length for future implementations should be determined by the speed distribution of the target road.

However, there are some limitations of this research. In general, the spatial arrangement and its own characteristics (i.e. size) of the stimuli will have influence on the fixation behaviour of drivers. Martín et al. (2017) found that the size of the object could influence the speed perception, size of single edge rate line may influence the speed perception, during road experiment, there the edge rate line length were difference as $\lambda$ changed, this difference may be influence the driver's speed perception and speed choice behaviour. It still needs a further explore.

\section{Acknowledgements and funding}

This work was supported by the National Natural Science Foundation of China (Grants No 71801176, 71771183) and the Scientific and Technological Project of the Ministry of Transport of China (Grant No 2010353342240).

We gratefully acknowledge the assistance of experiment participants.

\section{Author contributions}

Bing Liu and Shunying Zhu conceived the study and were responsible for the review and analysis of the theories of the speed perception and its application of edge rate lines.

Bing Liu, Shunying Zhu and Hong Wang were responsible for the experiment scheme.

Jing Xia and Naikan Ding responsible for the data collection and analysis.

Bing Liu was responsible for the data interpretation and wrote the first draft of the article.

\section{Disclosure statement}

We have no competing financial, professional, or personal interests from other parties.

\section{References}

AASHTO. 2011. A Policy on Geometric Design of Highways and Streets. American Association of State Highway and Transportation Officials (AASHTO). 934 p.
ATSSA. 2006. Low Cost Local Road Safety Solutions. American Traffic Safety Services Association (ATSSA). 48 p. Available from Internet: https://safety.fhwa.dot.gov/intersection/other_ topics/fhwasa09027/resources/Low\%20Cost\%20Local\%20 Road\%20Safety\%20Solutions.pdf

Carmel, D.; Lavie, N.; Rees, G. 2005. Neural correlates of conscious flicker perception, Journal of Vision 5(8): 768.

https://doi.org/10.1167/5.8.768

Denton, G. G. 1980. The influence of visual pattern on perceived speed, Perception 9(4): 393-402.

https://doi.org/10.1068/p090393

Ding, N.; Zhu, S. Y.; Wang, H.; Jiao, N. 2019. Effects of reverse linear perspective of transverse line markings on car-following headway: a naturalistic driving study, Safety Science 119: 50-57. https://doi.org/10.1016/j.ssci.2018.08.021

Ding, N.; Zhu, S.; Wang, H.; Jiao, N. 2017a. Effects of edge rate of the designed line markings on the following time headway, Scientia Iranica 24(4): 1770-1778.

https://doi.org/10.24200/sci.2017.4268

Ding, N.; Zhu, S.; Wang, H.; Jiao, N. 2017b. Following safely on curved segments: a measure with discontinuous line markings to increase the time headways, Iranian Journal of Science and Technology, Transactions of Civil Engineering 41(3): 351-359. https://doi.org/10.1007/s40996-017-0072-1

François, M.; Morice, A. H. P.; Bootsma, R. J.; Montagne, G. 2011. Visual control of walking velocity, Neuroscience Research 70(2): 214-219. https://doi.org/10.1016/j.neures.2011.02.003

Godley, S. T.; Triggs, T. J.; Fildes, B. N. 2000. Speed reduction mechanisms of transverse lines, Transportation Human Factors 2(4): 297-312. https://doi.org/10.1207/STHF2-4_1

Hallmark, S. L.; Knickerbocker, S.; Hawkins, N. 2013. Transverse speed bars for rural traffic calming, Tech Briefs (February): $1-3$.

Liu, B.; Zhu, S.; Wang, H.; Cheng, L. 2013. Optimization design and experiment on plane layout of edge line marking for speed reduction, in TRB 92nd Annual Meeting Compendium of Papers, 13-17 January 2013, Washington, DC, US, 1-18.

Longo, M. R.; Lourenco, S. F. 2007. Spatial attention and the mental number line: evidence for characteristic biases and compression, Neuropsychologia 45(7): 1400-1407.

https://doi.org/10.1016/j.neuropsychologia.2006.11.002

Martín, A.; Décima, A. P.; Barraza, J. F. 2017. Perception of speed, distance, and TTC of familiar objects, Psychology \& Neuroscience 10(3): 261-272. https://doi.org/10.1037/pne0000100

MassSAFE. 2004. Report on Passive Speed Control Devices. University of Massachusetts, US.

NHTSA. 2017. Traffic Safety Facts 2015: a Compilation of Motor Vehicle Crash Data from the Fatality Analysis Reporting System and the General Estimates System. Report DOT HS 812384. National Highway Traffic Safety Administration (NHTSA), US Department of Transportation, Washington, DC, US. 238 p. Available from Internet:

https://crashstats.nhtsa.dot.gov/Api/Public/ViewPublication/812384

Rakha, H. A.; Katz, B. J.; Duke, D. 2006. Design and evaluation of peripheral transverse bars to reduce vehicle speed, in TRB 85th Annual Meeting Compendium of Papers CD-ROM, 22-26 January 2006, Washington, DC, US, 1-14.

Recarte, M. A.; Nunes, L. M. 1996. Perception of speed in an automobile: estimation and production, Journal of Experimental Psychology: Applied 2(4): 291-304.

https://doi.org/10.1037/1076-898X.2.4.291 
Retting, R. A.; McGee, H. W.; Farmer, C. M. 2000. Influence of experimental pavement markings on urban freeway exitramp traffic speeds, Transportation Research Record: Journal of the Transportation Research Board 1705: 116-121. https://doi.org/10.3141/1705-17

Saffarian, M.; De Winter. J. C. F.; Senders, J. W. 2015. Measuring drivers' visual information needs during braking: a simulator study using a screen-occlusion method, Transportation Research Part F: Traffic Psychology and Behaviour 33: 48-65. https://doi.org/10.1016/j.trf.2015.07.001

Shen, H.; Shimodaira, Y.; Ohashi, G. 2005. Speed-tuned mechanism and speed perception in human vision, Systems and Computers in Japan 36(13): 1-12. https://doi.org/10.1002/scj.20369

Thompson, P. 1982. Perceived rate of movement depends on contrast, Vision Research 22(3): 377-380. https://doi.org/10.1016/0042-6989(82)90153-5

TMB PSM. 2017. Annual Statistics of Road Traffic Accidents of People's Republic of China 2016. Traffic Management Bureau of the Public Security Ministry (TMB PSM), China, Beijing (in Chinese).

Waldin, N.; Waldner, M.; Viola, I. 2017. Flicker observer effect: guiding attention through high frequency flicker in images, Computer Graphics Forum 36(2): 467-476.

https://doi.org/10.1111/cgf.13141 